Article

\title{
Investigating the Future of Ultrafast Charging: A Choice Experiment in the Netherlands
}

\author{
Simone Y. ten Have ${ }^{\dagger}$, Konstantinos Gkiotsalitis *(D) and Karst T. Geurs $\mathbb{D}$ \\ Faculty of Engineering Technology, Department of Civil Engineering, University of Twente, \\ Horst Complex Z222, 7500 AE Enschede, The Netherlands; s.y.tenhave@alumnus.utwente.nl (S.Y.t.H.); \\ k.t.geurs@utwente.nl (K.T.G.) \\ * Correspondence: k.gkiotsalitis@utwente.nl; Tel.: +31-53489-1870 \\ + Current address: APPM, Stationsplein 45, Unit D7.126, 3013 AK Rotterdam, The Netherlands.
}

Received: 29 September 2020; Accepted: 5 November 2020; Published: 7 November 2020

\begin{abstract}
Ultrafast charging is developing and will soon be available to electric vehicles (EV). This research focuses on the feasibility of ultrafast charging for EV passenger cars in the Netherlands. We carried out a stated choice experiment with 311 respondents (all EV drivers) and developed mixed logit models based on random utility maximization. In deciding which charging type to choose, this research identified the charging point characteristics, price, proximity to shopping facilities, certainty of charging availability and not having to make a detour as key influential factors for EV drivers. Price changes and not having to make a detour substantially affect users' choices for the charging types. Contrary to expectations, no significant results were found for urban density, age, technology awareness and importance of sustainability. Finally, the research results show that there is demand for ultrafast charging in the Netherlands even if users have to pay slightly more compared to other forms of charging.
\end{abstract}

Keywords: electric vehicles; charging behavior; ultrafast charging; stated preference; discrete choice modeling

\section{Introduction}

One of the main challenges in the large-scale introduction of electric vehicles (EVs) is the provision of a solid network of charging infrastructure. When designing a charging network there are several crucial aspects, such as the type of charging points. Developments in the type of charging affect consumers and policy decisions about refueling EVs. A recent and impactful development is ultrafast charging with a charging power of more than $350 \mathrm{~kW}$. Such charging power implies recharging $100 \mathrm{~km}$ of range in approximately three minutes or less, compared to hours of slow charging. One of the advantages of such a considerable reduction of charging times is that it might reduce the range anxiety. In the Netherlands, the first plug-in EVs were sold in 2011 and their sales have increased sharply since then. The term plug-in hybrid EV (PHEV) is internationally used for plug-in hybrid electric vehicles, whereas a full electric vehicle is a battery electric vehicle (BEV). The focus of this study is on $\mathrm{BEVs}$, since ultrafast charging is not yet suitable for PHEVs. Besides, PHEVs have an extended range due to their internal combustion engines and fast/ultrafast charging might be less critical for them. The number of registered electric vehicles in the Netherlands increased from 87,552 in December 2015 to 134,062 in October 2018 [1]. Aside from an PHEV or BEV, an electric vehicle can be a fuel cell EV (FCEV) which uses a fuel cell instead of a battery to power its electric motor.

Currently, the charging system in the Netherlands comprises of standard charging points $(<22 \mathrm{~kW})$, used for destination charging-another term for slow charging-and an increasing amount of fast charging points $(22-50 \mathrm{~kW})$. These fast charging points will likely become ultrafast charging 
points (350-450 kW) in the near future. In the Netherlands, the first ultrafast charging points were installed in July 2018 [2], even though vehicles cannot yet charge at such high speeds. It is unclear how the EV drivers will make use of such infrastructure when their vehicles are ready for this technology. This charging behavior is a key parameter in a well-functioning charging system. Ultrafast charging $(>350 \mathrm{~kW})$ has so far not been at the center of attention of scientific studies on EV charging, most likely because it is such a recent development [3-5].

In the literature, several studies on charging behavior have been conducted. It has repeatedly been found that the majority of EV charging takes place at homechargers [3,6,7], but it is argued that, despite this current trend, away-from-home charging is needed to grow BEV markets $[5,8]$. Such public infrastructure may include fast chargers $(>50 \mathrm{~kW})$, or in the near future, ultrafast chargers $(>350 \mathrm{~kW})$. Neaimeh et al. [5] explored the impacts of fast chargers on driving behavior in the US and the UK to demonstrate the importance of fast chargers. They found that both fast charging and slow charging have statistically significant and positive effects on daily distance, where the impact of fast charging is more influential than slow charging. Since better coverage of charging infrastructure increases the possibility to drive longer distances (and recharge halfway), it is expected that increased coverage of a fast charging network will increase EV adoption [9]. Vice versa, creating uncertainty about the availability of charging stations reduces the purchase intention for full EVs [10].

Hoekstra and Refa [11] found that Dutch EV drivers prefer good fast charging infrastructure over EVs with a very large vehicle range, and respondents strongly disagree with the idea that fast chargers of $50 \mathrm{~kW}$ can replace standard chargers [11]. However, ultrafast charging ( $>350 \mathrm{~kW})$ was not considered. Others have suggested that fast chargers might change roles with slow (destination) chargers [12], as only about $25 \%$ of Dutch households have access to a private parking space [11].

Few studies have examined the potential of ultrafast charging from a user perspective. Ultrafast charging could solve the parking and charging issues that are steadily developing due to waiting times for charging points, an increasing number of EVs, attractive pricing policies for parking at charging spots and more $[10,13]$. To the best of the authors' knowledge, the potential of ultrafast charging from a consumer perspective has not yet been studied, although some studies have suggested to pursue this line of research in order to improve charging infrastructure decisions [13].

This paper, therefore, aims at facilitating the understanding of EV driver behavior and to evaluate the potential of ultrafast charging in a constantly developing world of sustainable mobility. The objectives of this study were:

- To investigate the feasibility of ultrafast charging of EVs in the Netherlands following a user perspective.

- $\quad$ To identify the quantitative influence of key factors (e.g., pricing, availability) on the charging choices of EV drivers in the Netherlands.

- To investigate the sensitivity of charging type choices to potential attribute changes in future scenarios with the use of mixed logit models.

In this study, we address the research problem of identifying the quantitative influences of various factors (e.g., pricing and charging availability) on the charging choices of EV drivers in the Netherlands.

We contribute in this direction by investigating factors that possibly influence the consumers' choice between standard charging (up to $22 \mathrm{~kW}$ ), fast charging (around $50 \mathrm{~kW}$ ) and ultrafast charging $(>350 \mathrm{~kW})$. A survey with a stated choice experiment was conducted to explore such influential factors, and mixed logit (ML) models were estimated to identify factors that are important to EV drivers' choices for slow, fast and ultrafast charging points.

The remainder of this study is structured as follows. In Section 2 we detail our data collection through an online survey with a stated choice experiment among EV drivers in the Netherlands. The discrete choice modeling framework and the applications of mixed logit models are presented in Section 3. Finally, our results are discussed in Section 4 followed by our conclusion in Section 5. 


\section{Data Collection, Preparation and Description}

\subsection{Data Collection}

A stated choice experiment was distributed as part of a survey among EV drivers in the Netherlands. In our stated choice experiment the respondent was asked to choose among future options that did not exist yet. The focus of the survey was on regular EV passenger cars, excluding taxi transport and public transport. EV users themselves are most capable of comparing different charging type alternatives and selecting the best one, since they have firsthand experience of charging an EV. An attempt was made to include as many different EV users as possible, including lease drivers, EV owners and users of shared EVs. This study focuses on the Netherlands and Dutch EV users.

The survey starts with a screening question ("How often do you drive an EV?") and furthermore consists of the following parts: (A) questions on current mobility pattern, charging behavior and user satisfaction, (B) attitude statements, (C) the discrete choice experiment and (D) sociodemographic and personal characteristics. In the design of the stated choice experiment, the first step is to specify alternatives (the choice options) and their attributes and levels. The selection of factors to be included was based on the literature (e.g., [9,14-17]). The price attribute was based on the current price per $\mathrm{kWh}$ (the attribute levels can be found in Table 1). The kWh costs used in the research were based on current market prices for ultrafast charging and the other types of charging and they were confirmed by expert interviews. Ultrafast charging has a much higher $\mathrm{kWh}$ cost than slower charging because it is assumed that the installation, operation and maintenance have higher costs too-and this is reflected in the $\mathrm{kWh}$ price. After selecting the alternatives, attributes and levels, the choice sets were chosen; we created the experimental design and finally constructed the survey. Different designs were compared and an orthogonal design with the highest D-efficiency was chosen. An orthogonal design was desired since it is produced so as to have zero correlations between the attributes in the experiment, making it excellent for estimating linear models [18].

The D-efficiency of the design used in this study is 99.6. (see [19] for more information about the D-efficiency metric). Our selected design has 16 choice sets with four alternatives each. An example of a choice set used in the survey is shown in Figure 1. Initially, we performed pilot surveys in small groups of 8 and 10 respondents to improve the questionnaire before proceeding to the main survey. The main changes that were incorporated after the pilot surveys included a reduction of the amount of choice sets per survey and improvements in the formulation of the attitude statements. Using a blocking variable, four blocks of four choice sets were generated. Each respondent randomly received one of the four blocks. The entire choice experiment design can be found at the MSc thesis in [20].

Our online survey was created using the Web-based tool Qualtrics. It was distributed through several social media platforms (LinkedIn and Facebook) and through several organizations active in EV (namely, the electric drivers' association (VER), the national knowledge platform for charging infrastructure and the Dutch organisation for electric transport). The survey was open for responses from 1-28 April 2019. The complete survey can be found in Appendix A. 
Table 1. Attribute levels.

\begin{tabular}{|c|c|c|c|c|c|c|c|c|c|c|c|c|}
\hline \multirow[t]{2}{*}{ Set } & \multicolumn{4}{|c|}{ Ultrafast Charging } & \multicolumn{4}{|c|}{ Fast Charging } & \multicolumn{4}{|c|}{ Destination Charging } \\
\hline & Price & Facilities & Availability & Detour & Price & Facilities & Availability & Detour & Price & Facilities & Availability & Detour \\
\hline 1 & 11.76 & Shopping mall & Uncertain & No detour & 11.76 & Small shop or cafe & Certain & No detour & 5 & Waiting room & Certain & Detour \\
\hline 1 & 8.49 & Waiting room & Certain & Detour & 5 & Small shop or cafe & Certain & No detour & 15.25 & Shopping mall & Uncertain & Detour \\
\hline 1 & 8.49 & None & Uncertain & Detour & 15.25 & Shopping mall & Uncertain & No detour & 11.76 & Small shop or cafe & Certain & Detour \\
\hline 1 & 15.25 & None & Certain & Detour & 11.76 & Shopping mall & Certain & Detour & 8.49 & Small shop or cafe & Uncertain & No detour \\
\hline 2 & 15.25 & Waiting room & Certain & No detour & 5 & Small shop or cafe & Uncertain & Detour & 11.76 & None & Certain & Detour \\
\hline 2 & 8.49 & None & Certain & No detour & 15.25 & Waiting room & Uncertain & Detour & 5 & Shopping mall & Certain & No detour \\
\hline 2 & 5 & Small shop or cafe & Certain & No detour & 8.49 & Waiting room & Uncertain & Detour & 15.25 & None & Uncertain & Detour \\
\hline 2 & 8.49 & Shopping mall & Certain & Detour & 5 & None & Uncertain & Detour & 8.49 & Small shop or cafe & Uncertain & No detour \\
\hline 3 & 15.25 & None & Certain & Detour & 11.76 & Shopping mall & Uncertain & Detour & 8.49 & Waiting room & Certain & No detour \\
\hline 3 & 11.76 & Waiting room & Uncertain & No detour & 8.49 & None & Uncertain & No detour & 15.25 & Shopping mall & Certain & Detour \\
\hline 3 & 11.76 & Small shop or cafe & Uncertain & Detour & 5 & Shopping mall & Uncertain & Detour & 15.25 & Waiting room & Certain & No detour \\
\hline 3 & 8.49 & Shopping mall & Uncertain & No detour & 5 & Waiting room & Certain & No detour & 11.76 & Small shop or cafe & Certain & Detour \\
\hline 4 & 5 & Waiting room & Uncertain & Detour & 15.25 & Small shop or cafe & Uncertain & Detour & 8.49 & None & Certain & No detour \\
\hline 4 & 5 & None & Uncertain & No detour & 8.49 & Small shop or cafe & Certain & Detour & 11.76 & Waiting room & Uncertain & Detour \\
\hline 4 & 8.49 & Shopping mall & Certain & Detour & 5 & None & Uncertain & Detour & 11.76 & Waiting room & Uncertain & No detour \\
\hline 4 & 11.76 & None & Certain & No detour & 8.49 & Small shop or cafe & Uncertain & Detour & 5 & Shopping mall & Certain & No detour \\
\hline
\end{tabular}




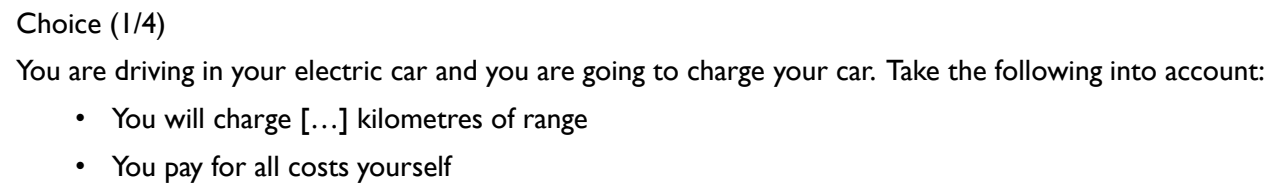

The duration and location of the charging session are fixed. The other variables vary per choice.

\begin{tabular}{|c|c|c|c|}
\hline & Ultrafast charging & Fast charging & Destination charging \\
\hline Duration of charging session & $3 \mathrm{~min}$ for $100 \mathrm{~km}$ & $20 \mathrm{~min}$ for $100 \mathrm{~km}$ & $4 \mathrm{hrs}$ for $100 \mathrm{~km}$ \\
\hline Location of charging session & On the route & On the route & At your destination \\
\hline Price of charging session & $€ 5,00$ for $100 \mathrm{~km}$ & $€ \mid 5,25$ for $100 \mathrm{~km}$ & $€ 8,49$ for $100 \mathrm{~km}$ \\
\hline Certainty of availability & No (waiting time unknown) & No (waiting time unknown) & Yes ( $<5$ min waiting time) \\
\hline $\begin{array}{l}\text { You have to make a detour } \\
\text { ( } 5 \text { min driving or walking) }\end{array}$ & Yes & Yes & No \\
\hline Facilities nearby & Covered waiting room & Small shop or café & None \\
\hline
\end{tabular}

Which type of charging do you choose?

\begin{tabular}{l|l|l|l} 
No preference & Ultrafast & Fast & Destination charging \\
\hline 0 & 0 & 0 & 0
\end{tabular}

Figure 1. Example of a choice set as used in the stated choice experiment. The input for "You will charge [...] kilometres of range" was taken from the previous question on the respondent's most recent charging session.

\subsection{Data Preparation}

The total number of respondents that participated in the survey is 311. From this, 265 indicated that they drive a BEV. The rest drive a plug-in hybrid vehicle and were excluded from the sample for this reason; $37 \mathrm{BEV}$ drivers were excluded because they had not completed the choice questions. A further 57 respondents were excluded because they opted for the same choice in all four scenarios, which indicates that the choice context was not properly defined for these respondents. This left 171 respondents to be analyzed. Since each respondent received four choices, a total of 684 observations can be regarded in the choice modeling procedure. Four respondents only made one out of four choices, which means 12 observations were excluded as these did not include a choice (three open choices $\times$ four respondents $=12$ observations). A final number of 672 observations are used in the remainder of this work.

All binary and categorical variables were dummy-coded for usage with the Biogeme software [21]. Concerning the attitude statements, the "do not know" option was only picked by one user per statement; thus it was decided to add those to the "neutral" category.

\subsection{Descriptive Statistics}

A direct comparison of our sample with the current population of Dutch EV drivers was not possible as there is no dataset available. However, data on EV vehicle types are available and comparisons of socio-economic characteristics of EV drivers is possible using earlier studies with surveys. The distribution of vehicle types within the sample was compared to publicly available data on all-electric vehicles in the Netherlands [22]. This indicates a rather good fit of the sample with respect to the vehicle types, as can be seen in Figure 2.

A comparison was made with available data of a large group of Dutch drivers who were interested in driving EV ( $n=694)$ [23]. This was one of the few studies on the characteristics of (future) Dutch EV drivers. The sample of 171 respondents in this research included considerably more highly educated people ( $80 \%$ compared to $38 \%$ in the Netherlands), males (90\% compared to $60 \%$ ) and people who live in strongly or extremely urbanized areas ( $43 \%$ compared to $25 \%$ ) than the population sampled by [23]; $43 \%$ of the sample was younger than 45 , while $64 \%$ of Dutch EV-enthusiasts were that age. This age variable is rather well distributed, with $19 \%$ aged $25-35,30 \%$ aged $35-45,31 \%$ aged between $45-55$ 
and $15 \%$ aged 55-65. This distribution, and the frequencies of =average length of regular trip in $\mathrm{km}$, are shown in Figure 3. It can be seen that most of the EV users have regular trip lengths between 5 and $100 \mathrm{~km}$, with some outliers in the direction of $300 \mathrm{~km}$.
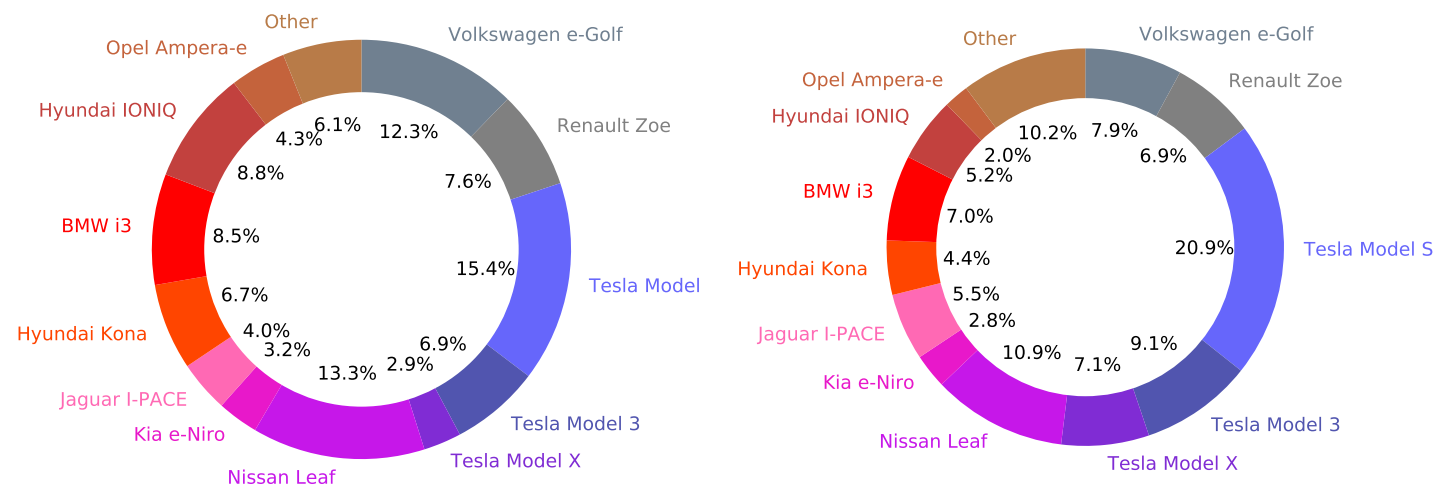

Figure 2. Distribution of vehicle types in the sample (left) and in the Netherlands (right).

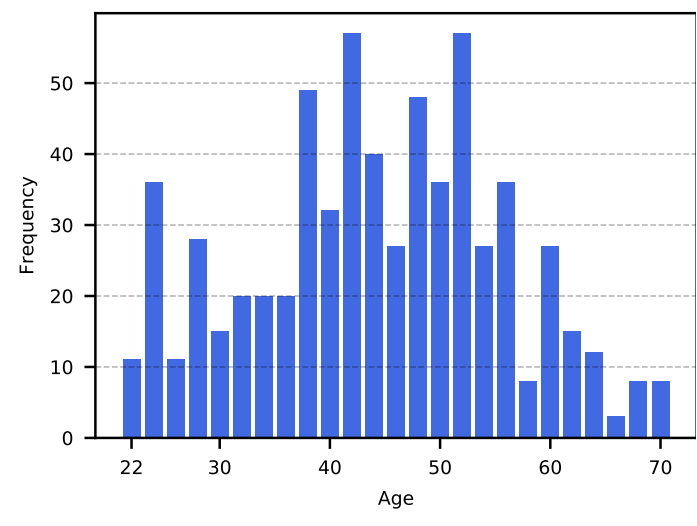

(a) Age in years

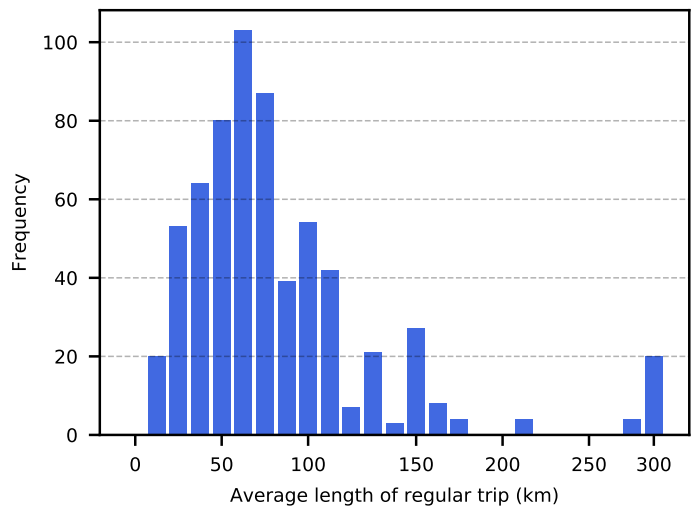

(b) Average length of regular trip $(\mathrm{km})$

Figure 3. Histograms for age and average trip length in $\mathrm{km}$. The youngest respondent was 23 years old; the oldest was 69 . The average trip length in $\mathrm{km}$ ranged from 0 to $300 \mathrm{~km}$; the last category captures respondents who answered $300 \mathrm{~km}$ or more.

The current sample has also been compared to a similar study that was conducted two years ago by [11]. Some frequencies of specific characteristics of the sample are shown in Table 2. It can be seen that the majority of the people $(84.5 \%)$ drive EVs four or more days a week, indicating a substantial charging need. The majority, $90.5 \%$, of the respondents were male (compared to $92 \%$ in Hoekstra and Refa [11]), whereas only $9.5 \%$ were female EV drivers. The variables income and education also have a very unequal distribution: many respondents had a high income ( $40 \%$ income of 77,500 euros or more) and were well-educated (42\% WO Bachelor and 34\% WO Master). In Hoekstra and Refa [11], 68\% of the respondents earned more than 50,000 on a yearly basis, and $73.7 \%$ had higher education, which is very similar to the sample in this study. It is decided not to use weights in this study due to the lack of data about the total population of Dutch EV drivers. Consequently, all results are specific to the studied sample. 
Table 2. Frequencies of EV driving, type of EV driver and gender of the sample $(n=171)$.

\begin{tabular}{lrlrlr}
\hline \multicolumn{2}{l}{ Frequency of EV Driving (\%) } & Type of EV Driver (\%) & \multicolumn{2}{l}{ Gender (\%) } \\
\hline$<$ 1 day per year & 0.6 & Ownership & 33.8 & Male & 90.5 \\
1-5 days per year & 0.6 & Private lease & 0.6 & Female & 9.5 \\
6-11 days per year & 0.6 & Business lease & 54.3 & & \\
1-3 days per month & 3.0 & Private car sharing & 0.6 & & \\
1-3 days per week & 10.7 & Business car sharing & 6.5 & \\
4 or more days per week & 84.5 & Other & 6.7 & \\
\hline
\end{tabular}

In Figure 4, one can see which percentage of respondents chose to use a certain type of charging and how often. It can be seen that destination charging at work, on-street slow charging and fast charging are used more than once a week by $25-55 \%$ of the respondents. In contrast, charging at sports clubs is the least popular, as about $75 \%$ of the respondents indicate using this type of charging less than one day per year. Interestingly, almost $40 \%$ of the respondents used fast charging 11 days or less per year, which means that a very large chunk of the EV drivers are not regular fast charger users. As to the question why people do not make use of fast charging at all (if they indicated they did not, $n=10)$, answers include that fast charging is not necessary $(n=3)$, it is too expensive $(n=1)$ and that one's car does not have the technology to fast charge $(n=6)$.

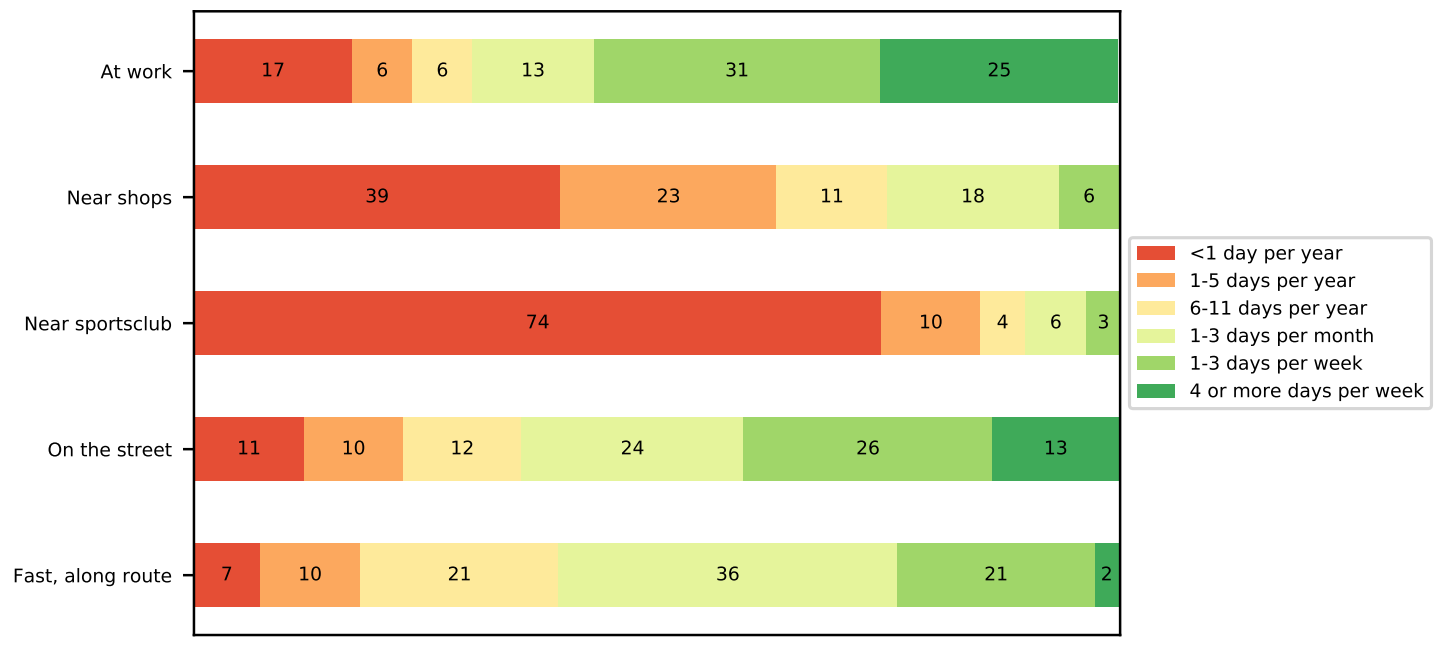

Figure 4. Charging frequencies for several locations (\%).

Without executing any model analysis yet, the respondents' choices show that there is a slight preference for ultrafast charging (34\%) compared to slow $(31 \%)$ and fast $(32 \%)$ charging. The no preference alternative was chosen in $3 \%$ of the choice scenarios. In Table 3, different sample segments are presented along with their choices. These variables are significantly related to choice, as can be seen in the right column of the table. Additionally, importance of travel costs is significantly related. However, since another cost variable (price) is explored in the choice models later, this is left out. Insignificant variables are not shown.

The Cramer's V test in Table 3 was executed for the categorical variables, investigating whether there is a relationship between the selected variables. When the Cramer's V statistic is significant, this means that the null hypothesis stating that there is no relationship can be rejected, thereby implying that there is a relationship. For the continuous variables, the ANOVA test procedure was used, using the $\mathrm{F}$ statistic in the same way as Cramer's V to test the independence between a continuous variable and a categorical variable (in this case choice). Note that this analysis of correlations is purely exploratory, meaning that relationships between variables are not taken into account. When the null hypothesis cannot be rejected, it does not necessarily mean that there is no relationship. 
It can be seen that the largest age group (41-50 years old) together with the youngest age group (23-30 years old) are the only groups among which the largest share opted for ultrafast charging. An interesting finding is that the respondents who valued driving comfort the most ("very important") chose ultrafast charging in most scenarios. The degree of urban density does not seem to encourage the choice of ultrafast charging. On the contrary, the "extremely urbanized" group favors slow charging most of the time, while the "not urbanized" group has a preference for ultrafast charging. These preliminary findings will be used to guide the model estimation process in a later stage.

Table 3. Choices made per sample segment by age, importance of driving comfort and degree of urban density. These variables are significantly related to the choice variable.

\begin{tabular}{|c|c|c|c|c|c|c|c|}
\hline \multirow[b]{2}{*}{ Variable } & \multirow[b]{2}{*}{ Segment } & \multirow{2}{*}{$\begin{array}{c}\text { Sample Composition } \\
\text { Freq }(\%)\end{array}$} & \multicolumn{4}{|c|}{ Choice } & \multirow[t]{2}{*}{$p$-Value for Variable } \\
\hline & & & Slow & Fast & Ultra & No & \\
\hline \multirow[t]{5}{*}{ Age } & 23-30 years & 13.1 & 39.8 & 15.9 & 40.9 & 3.4 & $0.001(\mathrm{~F}=5.215 ; \mathrm{df}=3)$ \\
\hline & $31-40$ years & 19.0 & 37.5 & 28.1 & 32.8 & 1.6 & \\
\hline & $51-60$ years & 23.8 & 25.0 & 37.5 & 35.0 & 2.5 & \\
\hline & $61-70$ years & 6.5 & 29.5 & 40.9 & 25.0 & 4.5 & \\
\hline & Unknown & 2.4 & 31.3 & 31.3 & 31.3 & 6.3 & \\
\hline $\begin{array}{l}\text { Importance of } \\
\text { driving comfort }\end{array}$ & Very important & 49.6 & 30.9 & 29.4 & 37.5 & 2.1 & \\
\hline \multirow[t]{4}{*}{ Degree of urban density } & Extremely urbanised & 16.7 & 43.8 & 23.2 & 30.4 & 2.7 & $0.002($ Cramer's V $=0.133)$ \\
\hline & Strongly urbanised & 26.8 & 26.1 & 42.2 & 30.6 & 1.1 & \\
\hline & Moderately urbanised & 14.9 & 26.0 & 27.0 & 44.0 & 3.0 & \\
\hline & Hardly urbanised & 20.8 & 34.3 & 24.3 & 35.7 & 5.7 & \\
\hline
\end{tabular}

\section{Model Estimation Results}

To investigate the influences that the variables have on the preferences of EV users and their uses of different charging types, we used discrete choice modeling based on the concept of utility maximization $[18,24,25]$. The utility function of individual $q$ when selecting a charging type alternative $j \in A=\left\{a_{1}, a_{2}, \ldots, a_{|A|}\right\}$ is $U_{j q}=U\left(x_{j q}\right)$ where $x_{j q}=x_{j q 1}, \ldots, x_{j q n}, \ldots, x_{j q k}$ is the vector of the attribute values for every alternative $j$ by the individual $q$. This is expressed by the following equation.

$$
U_{j q}=V_{j q}+\varepsilon_{j q}
$$

where $V_{j q}$ is the measurable, systematic part which is a function of the measured attributes $x$ (expressed as $V_{j q}=\sum_{n=1}^{k}\left(\beta_{j n} x_{j q n}\right)$ where $n \in\{1,2, \ldots, k\}$ and $\beta$ is constant for all individuals but possibly varying across alternatives). The second is a random part $\varepsilon_{j q}$ which reflects particular preferences of each individual, together with any measurement or observational errors made by the modeler $[24,26,27]$.

To maximize utility, individual $q$ selects the charging type alternative $j \in A$ if and only if:

$$
U_{j q} \geq \max _{i \in A} U_{i q}
$$

where the probability of choosing alternative $j \in A$ is given by $P_{j q}=\operatorname{Pr}\left(V_{j q}+\varepsilon_{j q} \geq \max _{i \in A}\left(V_{i q}+\varepsilon_{i q}\right)\right)$.

In this study we use standard mixed logit (ML) models that are highly flexible and can approximate any random utility model [28]. Mixed logit models allow for random taste variation, unrestricted substitution patterns and correlations in unobserved factors over time.

In ML, $\beta_{j}$ is not the same across all decision makers, but it is treated as a random variable $\beta_{j q}$ that follows a probability distribution $f(\beta \mid \theta)$ where $\theta$ are the parameters of the distribution of $\beta_{j q}$ over 
the population (i.e., mean and variance). Using mixed logit, the unconditional probability of decision maker $q$ choosing alternative $i \in A$ is the integral of the logit formula over the density of $\beta_{j q}$ :

$$
P_{i q}=\int L_{i q}(\beta) f(\beta \mid \theta) d \beta
$$

where $L_{i q}(\beta)$ is the logit probability evaluated at parameters $\beta_{j q}$, and $f(\beta \mid \theta)$ is a density function.

The mixed logit model estimation results are shown in Table 4 . The first column of this table refers to the mathematical notation as used in Equation (1). The columns of Table 4 titled "Value" contain the estimated parameter values of the variables named on the left. The columns titled "T-statistic" contain the value of the T-test, for which a value greater than $|1.96|$ indicates a significant contribution to the model [29]. In addition, the last row, $\rho^{2}$, uses the likelihood ratio index to measure how the model performs with the estimated values for the parameters compared to the null model (when all betas are equal to zero). If $\rho^{2}=1$, this indicates a perfect fit. However, Louviere et al. [24] state that a value of $\rho^{2}$ between 0.2 and 0.4 is considered to indicate good model fits.

Several ML models were estimated using the attributes included in the choice experiment. Variables were added one by one to the model. When they were insignificant, they were removed from the model. Three models are reported to show the steps that have been taken in the model estimation process. The ML models (1) and (2) contained 17 and 18 significant variables respectively, and the final ML model contained 21 significant variables. Using this approach, it can be tested whether the utility of an attribute depends on the alternative. For example, "certainty of availability" might be valued differently for the ultrafast alternative than for the slow charging alternative. It can be assumed that if an ultrafast charging point is not available at the moment the driver arrives, it will be very soon-while for slow charging this is not the case.

All models were estimated using alternative specific constants (ASCs), attributes of the choice experiment, socio-economic variables and attitude statement variables. Important to note is that the ASCs capture the errors ( $\varepsilon$ as in Equation (1)) associated with each alternative. The "no preference" alternative is used as the reference level in all models.

\subsection{Interpretation of the Mixed Logit Models}

In ML models (1) and (2), all parameters were estimated by adding variables one by one and using their significance as a criterion on whether to keep them in the model. ML models (1) and (2) were estimated as part of our process to arrive at the final model with the best fit. Respectively, 17 and 18 parameters were significant (at a 90\% significance level) for the reported models. Model (2) was retrieved after improving model (1). Several socio-economic variables were significant in ML model (1), including generic parameters for age, education for ultrafast charging and the importance of travel time for ultrafast charging. In the ML models, error components (the sigmas) were added to be able to estimate possible panel effects. These sigma parameters, together with the ASCs, explain part of the error $(\varepsilon)$ in the utility function, as mentioned in Equation (1). This error term ensures that the model is not biased, which is why also insignificant error components were kept in the models. Only the error component for ultrafast charging is significant and positive $\left(\varepsilon_{U} 2=0.548\right)$, indicating the presence of preference heterogeneity in the sampled population for this alternative [30]. This implies that respondents have a certain "loyalty" to this alternative. This could be because ultrafast charging is not yet possible but it seems an attractive new technology. Such respondent loyalty is not found for slow and fast charging. The estimated parameters can be seen in Table 4.

In ML model (2), the ASC for the ultrafast alternative was not significant at this point; however, it was kept in the model because it is a necessary and important part of the utility function. The values of the ASCs for all alternatives decreased in ML model (2). This decrease of ASCs indicates that a larger part of the utility of the alternatives is explained by the variables added to the model.

In both ML models (1) and (2), a generic parameter for no facilities was estimated. Its positive value indicates that for all charging types, the likelihood of choosing a certain charging type increases 
when there are no facilities present. For slow and fast charging this could be due to EV drivers' preferences to charge at their final destinations, whereas for ultrafast charging no facilities are necessary due to the very short charging sessions. In ML model (1), the importance of comfort (U) parameter was not significant, but importance of travel time (U) was. However, when further developing the model, this was reversed again in ML model (2).

A generic parameter for age was significant in ML model (1), indicating that when people are older, they are less likely to opt for any of the three alternatives. Since this is not realistic, the parameter was split into several alternative-specific parameters for age in ML model (2). This resulted in a negative parameter for the slow and ultrafast alternatives. These values imply that the younger people are, the more they tend to choose slow or ultrafast charging types. For fast charging, no conclusions can be drawn anymore, since the parameter was not found to be significant in this model.

Concerning the level of education, a positive parameter value for ultrafast charging indicates that one is more likely to opt for ultrafast charging when one has a higher level of education, and vice versa. Care should be taken when interpreting these results since the sample in this study had an above-average education level.

The final ML model provides the best fit to the data $\left(\rho^{2}=0.241\right)$, which is said to be a good model fit [24]. In Table 4, it can be seen that in the final model one error component $\left(\varepsilon_{U} 2\right)$ is found to be significant, which means there is preference heterogeneity of respondents towards the ultrafast charging alternative. The positive sigma value for ultrafast charging $\left(\varepsilon_{U 2}=0.548\right)$ indicates that respondents opted for the same alternative in different situations. It can be concluded that there is a panel effect for the ultrafast alternative, but this is not the case for the slow and fast alternatives. The sigma values for the latter two are insignificant, indicating that it is impossible to draw any conclusions on plausible panel effects.

The significant ASC values for slow and fast charging are lower than in the previous ML models, which means that more explanatory power is captured by the other estimated parameters in the model. Comparing the final ML model to the earlier models, the age parameter is no longer significant, the income parameters are included and significant and the generic parameter for no facilities has been replaced by two significant no facilities parameters for slow and fast charging. Higher income implies a lower tendency to opt for all three alternatives. This possibly indicates that public charging, compared to other (undefined) alternatives, is preferred less by people with higher incomes. The final model also shows that both slow and fast charging become more attractive when no facilities are present.

No significant values were found for gender and urban density in the models, and also age is no longer significant in the final ML model. This is encouraging because it avoids the dilemma of which interest to serve in policy-making. Governments and other stakeholders can ensure the installation of charging infrastructure in such a way that EV drivers consider all charging types as viable alternatives. The values for income and education indicate that a difference between income and education groups exists. However, this should be interpreted with caution as the sample includes many high-income and highly-educated individuals. 
Table 4. Model estimation results. This table only displays the significant factors, which is why not every attribute is mentioned for slow, fast and ultrafast. (S) refers to slow, (F) to fast and (U) to ultrafast.

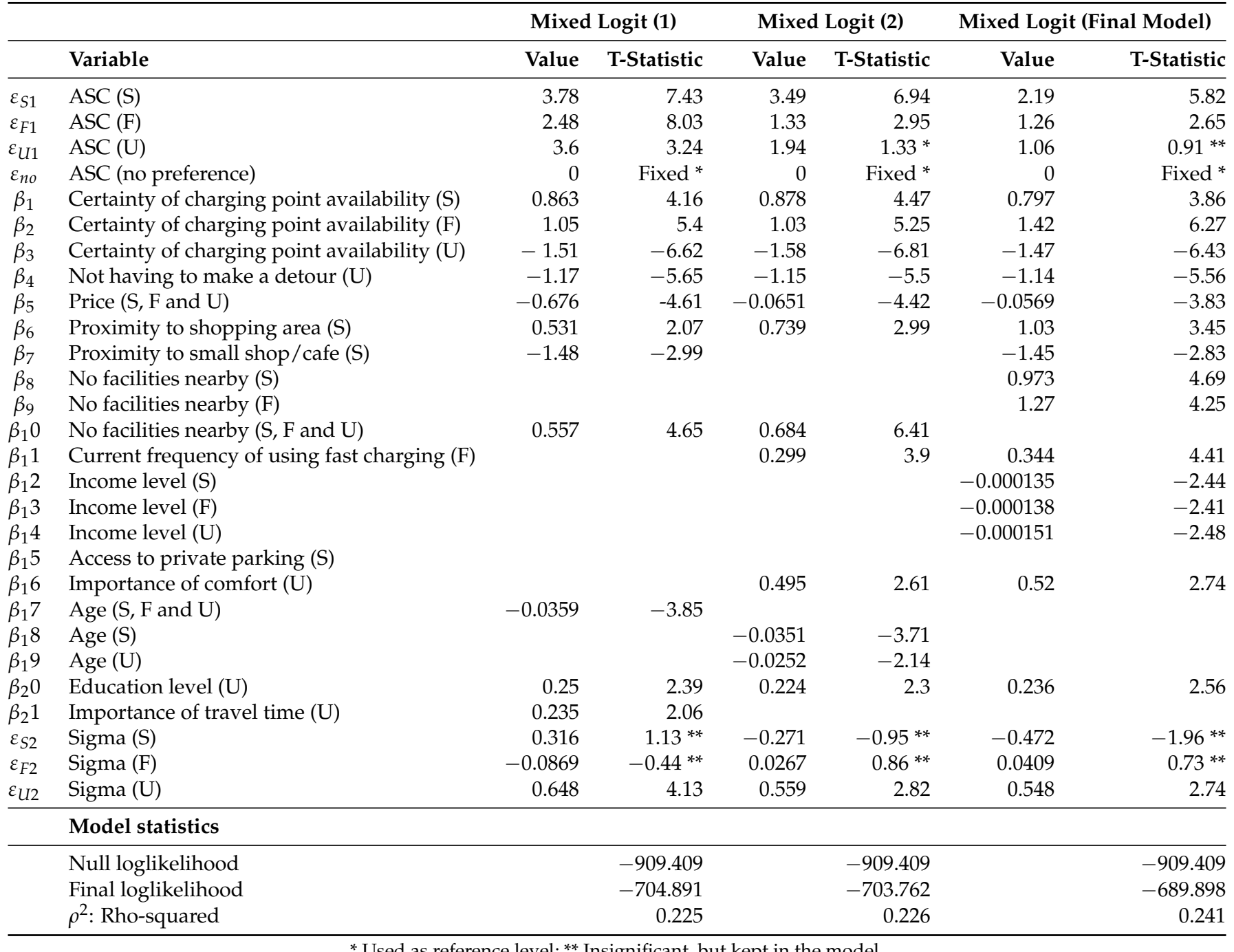

${ }^{*}$ Used as reference level; ** Insignificant, but kept in the model. 


\subsection{Model Application and Sensitivity Analysis}

The final mixed logit model with the best fit to the data was used to evaluate different scenarios with changing levels of the price and detour attributes. These attributes were chosen since price and location are most easily influenced by stakeholders. First, scenarios in which the price for slow charging and the price for ultrafast charging change are explored. Both scenarios are possible future situations in which a price change of either two alternatives pushes EV users into opting for another charging point type. The base scenario includes similar pricing for all three alternatives. Both direct-point and cross-point elasticities are calculated. Direct-point elasticities investigate the impact of a change of an attribute of alternative $j$ on the choice probability of the same alternative; cross-point elasticities measure the sensitivity of the model for alternative $j$ with respect to a modification of the attribute of another alternative [31]. These predicted probabilities of choice can be seen in Figure 5a,b. It can be observed that price has a substantial influence on the predicted probabilities of the sample, when keeping all other parameters constant. A price decrease for a certain alternative results in a higher predicted probability for the respective alternative. With all else being equal, the figures show that it was predicted that people are willing to pay slightly more for ultrafast charging than for slow charging, since the intersection of all alternatives occurs at a price increase of $25 \%$ for ultrafast charging and a price decrease of approximately $25 \%$ for slow charging. This price sensitivity should be taken into consideration when installing charging stations. For example, when high land prices increase slow charging prices, this will affect the choice probabilities of people opting for that alternative. In this direction, price change could be used as a steering mechanism by several stakeholders.

After this exploration of the influence of price changes in general, it is also interesting to explore the socio-economic characteristics. Since income was one of the socio-economic variables found to be significant in the final model, the probability distribution for different alternatives among income classes is examined. This can be seen in Figure 6. The income class "unknown" is not included. The other six defined income classes can be found on the horizontal axis of Figure 6. All else equal, when ultrafast charging becomes $50 \%$ cheaper, it has the highest predicted probability for all income classes except the lowest class. When ultrafast charging becomes $50 \%$ more expensive, it is a lot less attractive for the lowest income classes, as is logically expected. For the higher income classes, the predicted choice probabilities in Figure 6 are similar for all three alternatives when ultrafast prices increase. The most important conclusion from this is that there exists a possibly quite large difference between different income classes. It is interesting to observe that mainly for gross yearly incomes of 26,201-38,000 euros and higher, a different market-leading alternative can emerge due to price variations. When the Dutch EV driver population (and the used sample) is more diverse, this possible difference should be further explored.

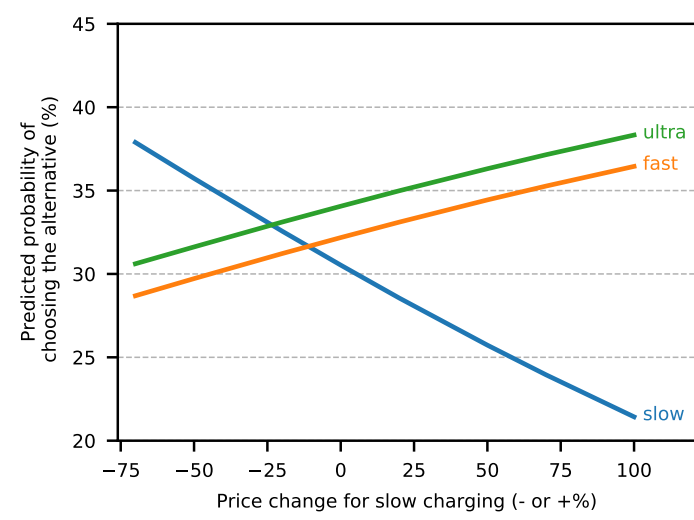

(a) Price changes for slow charging

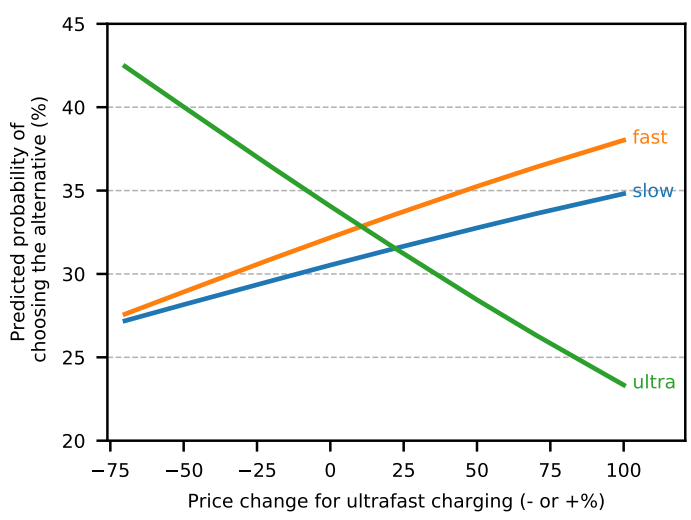

(b) Price changes for ultrafast charging

Figure 5. Predicted probabilities for scenarios with price changes per alternative. 


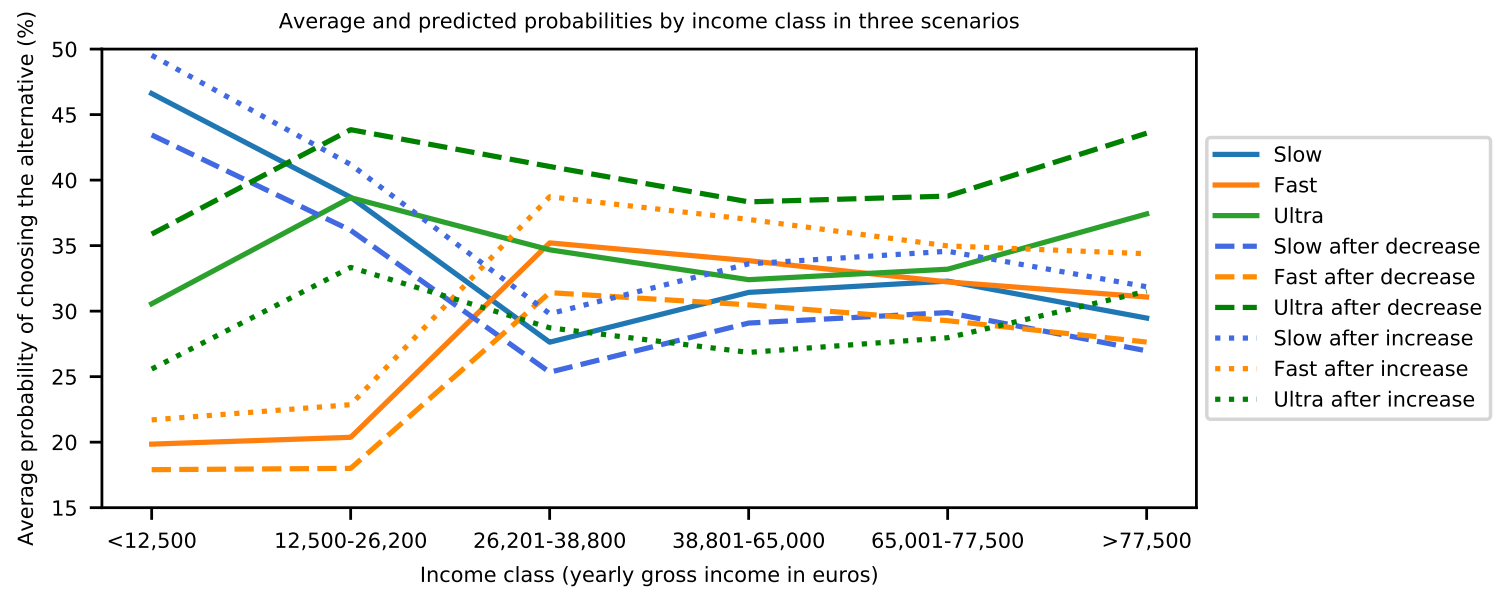

Figure 6. Probabilities per income class for scenarios with price changes for ultrafast charging. The scenarios include a 50\% price decrease for ultrafast charging, the base scenario and a $50 \%$ price increase for ultrafast charging.

Next, detour scenarios are explored. In Figure 7, three scenarios are shown: one in which people do not have to make a detour to get to an ultrafast charging point, the base scenario in which people sometimes have to make a detour and one in which people always have to make a detour to reach a charging point. The detour has a set length of five minutes in the model. The hypothetical scenario that no one ever has to make a detour for ultrafast charging indicates a future with an immense penetration rate of ultrafast charging points. In this case, the predicted probability that people opt for ultrafast charging along their route, with all else taken as equal, is $45.5 \%$ compared to $34 \%$ in the base scenario. Always having to make a detour makes the alternative a lot less attractive, looking at the predicted probability of only $23 \%$. This implies that for the installation of new charging points, it is advisable to focus on the most used roads and routes to determine optimal locations for charging.

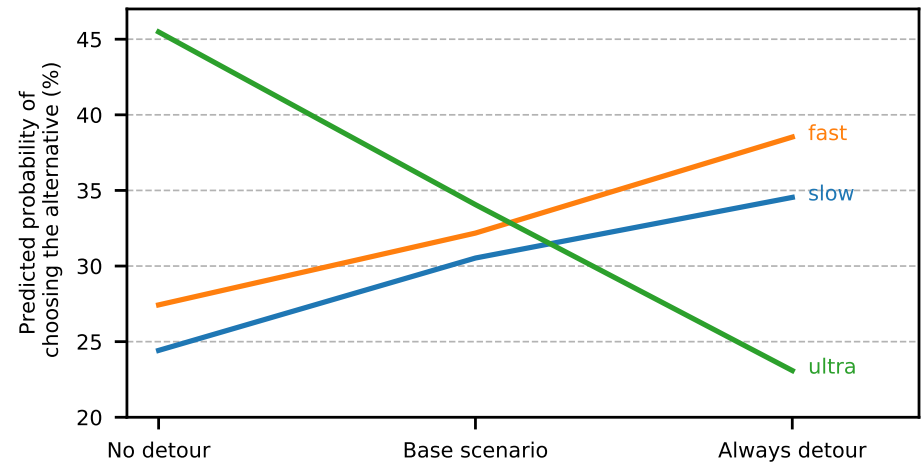

Figure 7. Predicted probabilities for a scenario with and without having to make a 5 min detour for an ultrafast charging point.

\section{Discussion}

The results of this study indicate that price; not having to make a detour; certainty of availability; proximity to shopping facilities; and the absence of facilities, income, education or comfort are important when selecting certain charging speed types. Several of these variables are in accordance with a previous study on user criteria for EV fast-charging locations, in which detours and shopping facilities were proven to be very important to users [32]. It should be noted that shopping facilities were chosen from several options where a "no-facilities" option was not included. In the remainder 
of this section, the interpretation of results, placing these results in a broader perspective and the limitations of this study are discussed.

\subsection{Interpretation of Results}

Users generally do not show a conclusively clear preference for ultrafast charging (chosen $34.1 \%$ of the time), indicating that this is not the one and only charging method to implement in the Netherlands. Part of this may be due to the currently well-functioning and covering destination charging infrastructure, shown by the current ratio of only 0.97 BEVs per public or semi-public charging point [1]. This may be subject to change when the number of BEVs will continue to increase in the coming years $[4,12,33]$. In this research, it was found that some preference heterogeneity for ultrafast charging (panel effect) plays a role in the user's choice, which is likely to be explained by the influence of habits on decisions, as mentioned in the literature [34]. However, even though this might be true, a significant value was only found for the current usage frequency of fast charging influencing the tendency to opt for fast charging. Other variables concerning the current usage frequency of charging points at different locations were not significant.

The estimated parameter values for certainty of availability are interesting to investigate since their sign is not similar across alternatives. The reasons for this cannot be explained just by looking at the model results. The responses of people about this parameter might have been due to their current main reason to use fast charging, as investigated by [35]. This reason is "time left and possibility to charge," indicating that people use faster charging only when it is available. This may distort the results of the choice model as people might take availability as a prerequisite and only look at other parameters when making their choices. This is a noticeable result, as charging availability issues occur repeatedly in the Netherlands (e.g., [36]). Such issues are assumed to be less apparent for faster charging since the duration of the sessions is much shorter. This leads to the expectation that the availability should be most important for slow charging; however, this was not the case in the model.

The parameter not having to make a detour is negative for ultrafast charging, implying that when no detour has to be made, the alternative becomes less attractive-which is not in line with expectations. That is also contradictory to what was found in earlier studies on fueling locations: drivers prefer to recharge along their frequently used routes [37]. It can be said that, when also considering the significant results of proximity to a shopping area, proximity to a small shop or cafe and no facilities for some alternatives, the location of the charging point is important to the user. Additionally, when people find comfort important, this increases their tendency to opt for ultrafast charging, indicating that the comfort associated with ultrafast charging is valued highly by Dutch EV users.

A sensitivity analysis was executed on the models used in this research. Since linear models were estimated, simple elasticity calculations could be applied to retrieve results. As expected, price and whether or not having to make a detour influenced choice probabilities of the alternatives in the expected directions. Interestingly, income classes did not follow a straightforward pattern, indicating that there probably are other moderating or explanatory variables that impact the probabilities found. Comparing this finding to the result of the final ML model, it is also possible that higher income classes have a lower preference for public charging. Private homecharging could well be their first choice.

\subsection{Placing Results in a Broader Perspective}

Fast changes in the automotive industry concerning both cars and batteries might have large impacts on the future use of charging infrastructure types. Satisfaction levels of current infrastructure may decrease, and ultrafast charging might rise as a plausible alternative. A possible contextual variable might be the generally short distances driven in the Netherlands, which might not be the ideal environment to implement a network of ultrafast chargers. Regular fast or destination charging might just be enough. However, when price and location are selected well, ultrafast charging is certainly an option for EV drivers, as can be deduced from the models. Such pricing and location decisions 
can be influenced by businesses as well as government stakeholders, making ultrafast charging an interesting alternative.

Future developments that are hard to predict will likely impact the success of ultrafast charging in the Netherlands. An example of such a development is smart charging in combination with vehicle-to-grid or vehicle-to-home technologies, which are generally only useful for slow charging. Automotive industry innovations in cars and batteries will also impact the level playing field. In addition, developments in costs per $\mathrm{kWh}$, as well as costs for newly installed infrastructure (hardware and grid connections), will influence the feasibility of ultrafast charging as primary charging mode. A future consideration that puts ultrafast charging in a positive light is the impact charging infrastructure has on public space. When the masses start driving BEVs, it is questionable whether primarily slow charging could cover the charging needs of all users. Since faster charging points can serve more customers in less time, this would be more practical and additionally put less pressure on public space.

\section{Conclusions}

The aim of this research was to investigate the feasibility of ultrafast charging in the Netherlands, from a user perspective. In a choice modeling procedure, several ML models were estimated to retrieve the quantitative influence of various factors on the EV driver choices for different charging types. From the descriptive analysis of the sample of EV users of this research, several remarks can be made about the current charging behavior in addition to what is known from recent literature. Most of the $\mathrm{EV}$ users have regular trip lengths between 5 and $100 \mathrm{~km}$, with some outliers having trips in the range of $300 \mathrm{~km}$. The majority of the sample $(84.5 \%)$ drove an EV four or more days a week, indicating a substantial charging need. Slow charging at work or on-street, and fast charging were used more than once a week by $25-55 \%$ of the respondents. Interestingly, almost $40 \%$ of the respondents used fast charging 11 days or less per year, indicating that a very large part of the EV drivers is not a regular fast charger.

Regarding the factors that influence the charging of EVs, all charging point characteristics (which were attributes in the choice sets) were found to have significant influences on the estimated ML models, whereas only some user characteristics play roles. One attitude variable, several socio-economic variables and one charging behavior variable were found to be significant in the final ML model. This means that satisfaction levels, travel behavior variables and vehicle characteristics did not have substantial influences on the user choice, as found in this research. All researched charging point characteristics were found to be significant, including price and proximity to facilities. Price was found to have a negative relationship with the utility of ultrafast, fast and slow charging alternatives. This means that a lower price for an alternative makes that alternative more attractive. It should be mentioned that the current prices used in this research are found to be competitive. On the market, the price for ultrafast charging will be dependent on the availability of other charging types, due to supply and demand. A slow charging point located next to a shopping area boosts the utility of this charging alternative. However, respondents also have a higher tendency to opt for fast and slow charging points without facilities. Noticeable is a decrease in utility of slow charging linked to access to private parking when one would have expected the opposite. Finally, comfort is the only attitude variable that was significant in the model.

Summarizing the model outcomes and stakeholder attitudes, a feasible scenario exists for the development of ultrafast charging in the Netherlands. However, it might not become the dominant charging type in the Netherlands. The results of this research may have implications for the charging infrastructure policy in the Netherlands. The results indicate that a sole focus on ultrafast charging is not the ideal way forward since people also express a preference for regular fast and destination (slow) charging. A mix of these options is recommended. All else equal, when building charging infrastructure anew, it is definitely interesting to consider focusing on ultrafast charging.

Further research could go several directions. Firstly, future research into user preferences for ultrafast charging could focus on the impacts of charging locations, related to possible necessary 
detours and installed facilities. The differences between facilities and final destinations should be incorporated in follow-up research. The careful analysis of the locations of ultrafast chargers is also required, especially at the early stages of deployment where the penetration of ultrafast chargers will be low. Secondly, the influence of income on charging choices is also interesting to further explore, since from this research it seems likely that more variables have an impact on this relationship. Thirdly, it would also be interesting to study non-EV drivers, although the presence of required pre-knowledge on EV charging should be carefully considered. Fourthly, this paper focused on the user perspective in EV-charging. Further research could be directed at examining the potential of ultrafast charging from government and business perspectives, including investment costs, public space and business models that should eventually align with user preferences as well as with government regulations. Of particular interest is the availability of the extensive funding that will be required for unltrafast charging stations. Finally, one might further investigate the trade-off between the battery longevity and the potential EV drivers' earnings associated with vehicle-to-grid (V2G) for ultrafast charging.

Author Contributions: Conceptualization, S.Y.t.H. and K.T.G.; methodology, S.Y.t.H., K.G., K.T.G.; software, S.Y.t.H.; validation, S.Y.t.H.; formal analysis, S.Y.t.H.; investigation, S.Y.t.H.; resources, S.Y.t.H.; data curation, S.Y.t.H.; writing —original draft preparation, S.Y.t.H.; writing-review and editing, K.G., K.T.G.; visualization, S.Y.t.H. and K.G.; supervision, K.G. and K.T.G.; project administration, S.Y.t.H.. All authors have read and agreed to the published version of the manuscript.

Funding: This research received no external funding.

Conflicts of Interest: The authors declare no conflict of interest.

\section{Appendix A. Survey Questionnaire}

Q1. Do you agree sharing your data?

Q2. Screening question: How often do you drive an electric vehicle?

- 4 days per week or more

- 1-3 days per week

- 1-3 days per month

- 6-11 days per year

- $1-5$ days per year

- $\quad<1$ day per year

- $\quad$ Never (will be sent to end of survey)

For the remaining questions in the survey, if you drive more than one EV, please consider the EV you drive the most.

Q3. What kind of electric vehicle do you drive most of the time?

- Full electric vehicle (1)

- Hybrid (2)

- $\quad$ Fuel cell electric vehicle (3)

Q4. Which brand and type of hybrid car do you drive? Display if $Q 3=2$

- $\quad$ Toyota Prius (1)

- Mitsubishi Outlander (2)

- Volkswagen Golf GTE (3)

- Volkswagen Passat GTE (4)

- Opel Ampera Hybride (5)

- Audi A3 e-tron (6) 
- Other, (7)

Q5. Which brand and type of EV do you drive? Display if $Q 3=3$

- Nissan Leaf (4)

- Hyundai IONIQ (5)

- Volkswagen e-Golf (6)

- $\quad$ Tesla Model 3 (7)

- $\quad$ Tesla Model S (8)

- Tesla Model X (9)

- Renault Zoe (10)

- $\quad$ BMW i3 (11)

- Jaguar I-PACE (12)

- Hyundai Kona (13)

- Kia e-Niro (14)

- Opel Ampera-e (15)

- Other (16)

If $Q 3=1$, one is sent to the end of the survey as this is not the target group.

Q6. Do you own the EV that you drive?

- No, business lease

- No, private lease

- Yes

- No, business car sharing

- No, private car sharing

- Other,

Q7. For which purpose do you use the EV the most often?

- Private trips

- Commuting

- Business (e.g., trip to client or customer)

- Bestel/logistiek

- Taxi

- Other,

Q8. How many months of experience do you have in driving an electric vehicle? months (dropdown question 1, 2, $3 \ldots 60$ and more than 60 months)

Q9. Do you have access to private parking at home? (E.g. own driving lane)

- Yes

- No

Q10. Are there, next to the EV you use the most, other cars in your household that you can use?

- Yes, 1 other car

- Yes, 2 other cars

- Yes, 3 or more other cars

- No 
How many kilometres.... (Sliding scale $0-300$, if $=$ more than 300,300 is selected)

Q11. Do you drive on a regular trip with your EV (one way)?

Q12. Is your most recent made trip with EV (one way)?

Q13. Was your longest trip you ever made with EV (one way)? (up to $1200 \mathrm{~km}$ )

For this study, a distinction is made between different charging types based on speed. These are the following:

(1) Destination charging (slow charging): you charge $100 \mathrm{~km}$ of range in $4 \mathrm{~h}$. Usually on the street (curbside), at work, or for example at a sportsclub.

(2) Fast charging: you charge $100 \mathrm{~km}$ of range in $30 \mathrm{~min}$. You find these chargers along the highway, or at several locations like Van der Valk hotels.

(3) Ultrafast charging: you charge $100 \mathrm{~km}$ in less than $3 \mathrm{~min}$. More and more of these chargers are installed in the Netherlands in public areas, usually at locations similar to those of fast charging.

Q14. How often do you make use of destination charging at the following locations?

\begin{tabular}{|c|c|c|c|c|c|c|}
\hline & $\begin{array}{r}4 \text { Days Per } \\
\text { Week or More }\end{array}$ & $\begin{array}{l}\text { 1-3 Days } \\
\text { Per Week }\end{array}$ & $\begin{array}{r}\text { 1-3 Days } \\
\text { Per Month }\end{array}$ & $\begin{array}{r}\text { 6-11 Days } \\
\text { per Year }\end{array}$ & $\begin{array}{l}<1 \text { Day } \\
\text { Per Year }\end{array}$ & Never \\
\hline At work & $\mathrm{o}$ & $\mathrm{o}$ & $\mathrm{O}$ & $\mathrm{o}$ & $\mathrm{o}$ & $\mathrm{o}$ \\
\hline At sportclubs, fitness or comparable & $\mathrm{o}$ & $\mathrm{o}$ & $\mathrm{o}$ & $\mathrm{O}$ & $\mathrm{o}$ & $\mathrm{o}$ \\
\hline On the street (curbside) & $\mathrm{o}$ & $\mathrm{o}$ & $\mathrm{o}$ & $\mathrm{O}$ & o & $\mathrm{o}$ \\
\hline
\end{tabular}

Q15. How often do you make use of fast charging?

- 4 days per week or more

- 1-3 days per week

- $1-3$ days per month

- 6-11 days per year

- $1-5$ days per year

- $\quad<1$ day per year

- Never

Q16. Do you have a private driveway?

- Yes

- No

Q17. Do you have a private charger at home? (Only displayed if Q16 = yes)

- Yes

- No

Q18. How often do you make use of your private charger? (Displayed if Q17 = yes)

- 4 days per week or more

- 1-3 days per week

- 1-3 days per month

- 6-11 days per year 
- $1-5$ days per year

- $\quad<1$ day per year

- Never

Q19. If (never), why not?

- My car cannot fast charge

- Other,

Q20. If ( $<1$ day per year) or more, why? You can list more than one reason.

- My range was not sufficient to complete my trip, so I need to fast charge along the way.

- The charging point I wanted to use was occupied, malfunctioning or inoperative (buiten werking).

- My visit to a certain location was too short to charge $(<2 \mathrm{~h})$, so I needed fast charging.

- I simply prefer fast charging over slow charging.

- There is no charging point at my destination.

- It is cheap.

- The charging speed is high.

- I use fast charging if I have time left and I see a possibility of fast charging.

- I do not have a charging point close to my home.

- Other,

Q21. To what extent do you agree with the following statements on current public charging infrastructure in the Netherlands?

\begin{tabular}{|c|c|c|c|c|c|}
\hline & $\begin{array}{r}\text { Totally } \\
\text { Disagree }\end{array}$ & Disagree & $\begin{array}{r}\text { Neither Agree } \\
\text { nor Disagree }\end{array}$ & Agree & $\begin{array}{r}\text { Totally } \\
\text { Agree }\end{array}$ \\
\hline There are enough charging points & o & $\mathrm{o}$ & o & o & o \\
\hline The speed of charging points is high enough & o & $\mathrm{o}$ & o & o & o \\
\hline $\begin{array}{l}\text { The information on prices of charging points } \\
\text { is enough }\end{array}$ & o & o & $\mathrm{o}$ & o & o \\
\hline $\begin{array}{l}\text { The information on availability of charging } \\
\text { points is enough }\end{array}$ & o & o & o & o & o \\
\hline
\end{tabular}

Q22. How important do you find the following aspects of public charging infrastructure?

\begin{tabular}{rccccc}
\hline & $\begin{array}{c}\text { Very } \\
\text { Unimportant }\end{array}$ & Unimportant & Neutral & Important & $\begin{array}{c}\text { Very } \\
\text { Important }\end{array}$ \\
\hline The number of charging points & $\mathrm{o}$ & $\mathrm{o}$ & $\mathrm{o}$ & $\mathrm{o}$ & $\mathrm{o}$ \\
Speed of charging & $\mathrm{o}$ & $\mathrm{o}$ & $\mathrm{o}$ & $\mathrm{o}$ & $\mathrm{o}$ \\
Information on prices of charging points & $\mathrm{o}$ & $\mathrm{o}$ & $\mathrm{o}$ & $\mathrm{o}$ & $\mathrm{O}$ \\
Information on availability of charging points & $\mathrm{o}$ & $\mathrm{o}$ & $\mathrm{o}$ & $\mathrm{o}$ & $\mathrm{o}$ \\
\hline
\end{tabular}

Q23. To what extent do you agree with the following statements?

It is very important to me to...

\begin{tabular}{|c|c|c|c|c|c|}
\hline & $\begin{array}{r}\text { Totally } \\
\text { Disagree }\end{array}$ & Disagree & $\begin{array}{r}\text { Neither Agree } \\
\text { nor Disagree }\end{array}$ & Agree & $\begin{array}{r}\text { Totally } \\
\text { Agree }\end{array}$ \\
\hline ... travel sustainably. & o & o & o & o & $\mathrm{o}$ \\
\hline ... minimise my travel costs. & o & o & $\mathrm{o}$ & o & $\mathrm{o}$ \\
\hline ... travel comfortably. & o & o & o & o & $\mathrm{O}$ \\
\hline$\ldots$ minimise my travel time. & $\mathrm{o}$ & o & o & o & $\mathrm{o}$ \\
\hline$\ldots$ be up to date with the newest technologies. & $\mathrm{o}$ & o & $\mathrm{o}$ & o & $\mathrm{o}$ \\
\hline
\end{tabular}


Q24. How many kilometres of range did you charge during your most recent charging session?

- $\quad 0-50 \mathrm{~km}$

- $\quad 50-100 \mathrm{~km}$

- $\quad 100-150 \mathrm{~km}$

- $150-250 \mathrm{~km}$

- $\quad$ More than $250 \mathrm{~m}$

For the next 4 questions you will be asked to make a choice between 4 alternative charging options. You can choose between Ultrafast charging, Fast charging, Destination (Slow) charging or No preference.

For each choice, take the following into account:

- You will charge (...) kilometres (Answer category used in Q24)

- You pay for all costs yourself.

The duration and location of the charging session are fixed. The other variables vary per choice.

\section{(RANDOMIZER: 1 OUT OF 4 CHOICE BLOCKS OF 4 CHOICES DISPLAYED)}

You are almost at the end of the survey. We would only like to know something more about your personal characteristics.

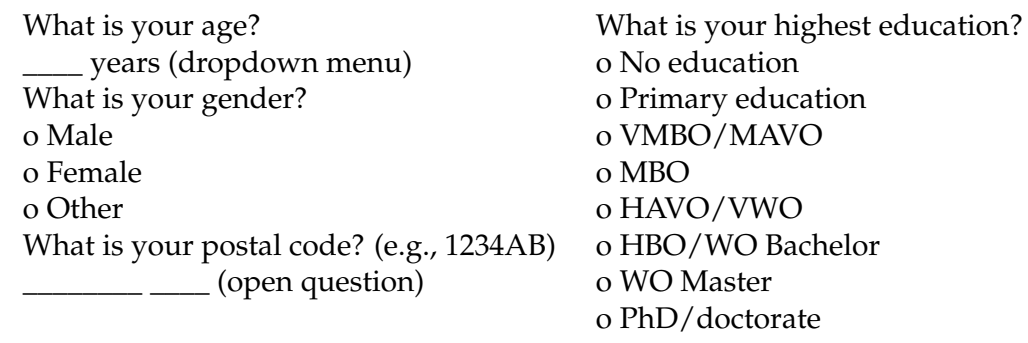

What is your annual gross income? $\mathrm{o}<12.500$

o $12.500-26.200$

o $26.201-38.800$

o $38.801-65.000$

o $65.001-77.500$

o $>77.500$

o I don't know

\section{References}

1. RVO. Statistics Electric Vehicles and Charging in The Netherlands up to and including October 2018. 2018. Available online: https:/ / www.rvo.nl/file/statistics-electric-vehicles-and-charging-netherlands-and-includ ing-october-2018 (accessed on 18 November 2018).

2. Allego. First MEGA-E High Power Charging Network Site Opened in Europe. 2018. Available online: https:/ / www.allego.eu/ first-mega-e-high-power-charging-network-site-opened-in-europe/ (accessed on 20 November 2018).

3. Hardman, S.; Jenn, A.; Tal, G.; Axsen, J.; Beard, G.; Daina, N.; Witkamp, B. A review of consumer preferences of and interactions with electric vehicle charging infrastructure. Transp. Res. Part D 2018, 62, 508-523. [CrossRef]

4. Gnann, T.; Funke, S.; Jakobsson, N.; Plötz, P.; Sprei, F.; Bennehag, A. Fast charging infrastructure for electric vehicles: Today's situation and future needs. Transp. Res. Part D Transp. Environ. 2018, 62, 314-329. [CrossRef]

5. Neaimeh, M.; Salisbury, S.D.; Hill, G.A.; Blythe, P.T.; Scoffield, D.R.; Francfort, J.E. Analysing the usage and evidencing the importance of fast chargers for the adoption of battery electric vehicles. Energy Policy 2017, 108, 474-486. [CrossRef]

6. Franke, T.; Krems, J. Understanding charging behaviour of electric vehicle users. Transp. Res. Part F 2013, 21,75-89. [CrossRef]

7. Funke, S.A.; Plötz, P. A techno-economic analysis of fast charging needs in Germany for different ranges of battery electric vehicles. In Proceedings of the European Battery, Hybrid and Fuel Cell Electric Vehicle Congress, Geneva, Switzerland, 14-16 March 2017; pp. 1-7. 
8. Caperello, N.; Tyreehageman, J.; Davies, J. I am not an environmental wacko! Getting from early plug-in vehicle owners to potential later buyers. In Proceedings of the Transportation Research Board 94th Annual Meeting, Washington, DC, USA, 11-15 January 2015.

9. Axsen, J.; Kurani, K. Hybrid, plug-in hybrid, or electric-What do car buyers want? Energy Policy 2013, 61, 532-543. [CrossRef]

10. Wolbertus, R.; Kroesen, M.; Van den Hoed, R.; Chorus, C. Policy effects on charging behaviour of electric vehicle owners and on purchase intentions of prospective owners: Natural and stated choice experiments. Transp. Res. Part D 2018, 62, 283-297. [CrossRef]

11. Hoekstra, A.; Refa, N. Characteristics of Dutch EV drivers. In Proceedings of the EVS30 Symposium, Stuttgart, Germany, 9-11 October 2017.

12. Ecofys. Toekomstverkenning Elektrisch Vervoer. 2016. Available online: https://www.rijksoverheid.nl /documenten/rapporten/2016/12/06/eindrapport-toekomstverkenning-elektrisch-vervoer (accessed on 1 January 2019).

13. Wolbertus, R.; Kroesen, M.; Van den Hoed, R.; Chorus, C. Fully charged: An empirical study into the factors that influence connection times at EV-charging stations. Energy Policy 2018, 123, 1-7. [CrossRef]

14. Björnsson, L.; Karlsson, S. Plug-in hybrid electric vehicles: How individual movement patterns affect battery requirements, the potential to replace conventional fuels, and economic viability. Appl. Energy 2015, 143, 336-347. [CrossRef]

15. Dong, J.; Liu, C.; Lin, Z. Charging infrastructure planning for promoting battery electric vehicles: An activity-based approach using multiday travel data. Transp. Res. Part C Emerg. Technol. 2014, 38, 44-55. [CrossRef]

16. Figenbaum, E. Perspectives on Norway's supercharged electric vehicle policy. Environ. Innov. Soc. Transit. 2017, 25, 14-34. [CrossRef]

17. Nicholas, M.; Tal, G. Charging for Charging at Work: Increasing the Availability of Charging through Pricing. In Proceedings of the Transportation Research Board 94th Annual Meeting, Washington, DC, USA, 11-15 January 2015.

18. Ortúzar, J.; Willumsen, L.G. Modelling Transport; John Wiley \& Sons, Ltd.: Chichester, UK, 2011.

19. Kuhfeld, W. Marketing Research Methods in SAS: Experimental Design, Efficiency, Coding, and Choice Designs; SAS Institute Inc.: Cary, NC, USA, 2010; pp. 53-233.

20. ten Have, S. Is Ultrafast Charging the Future for Electric Vehicles in the Netherlands? A Discrete Choice Experiment on User Preferences for Slow, Fast and Ultrafast Charging. Master's Thesis, University of Twente, Enschede, The Netherlands, 2019.

21. Bierlaire, M. BIOGEME. In Proceedings of the 3rd Swiss Transportation Research Conference, Ascona, Switzerland, 19-21 March 2003.

22. RDW. Open Data Elektrische Voertuigen. 2019. Available online: https://opendata.rdw.nl/Voertuigen/Ele ktrische-voertuigen/w4rt-e856 (accessed on 1 July 2019).

23. ANWB. ANWB Elektrisch Rijden Monitor. 2019. Available online: https://www.anwb.nl/binaries/content /assets/anwb/pdf/belangenbehartiging/mobiliteit/rapport-erm-def.pdf (accessed on 1 July 2019).

24. Louviere, J.; Hensher, D.; Swait, J. Stated Choice Methods: Analysis and Application; Cambridge University Press: Cambridge, UK, 2000.

25. Gkiotsalitis, K.; Stathopoulos, A. A utility-maximization model for retrieving users' willingness to travel for participating in activities from big-data. Transp. Res. Part C Emerg. Technol. 2015, 58, 265-277. [CrossRef]

26. Lancaster, K. A New Approach to Consumer Theory. J. Political Econ. 1966, 74, 132-157. [CrossRef]

27. Gkiotsalitis, K.; Stathopoulos, A. Predicting Traveling Distances and Unveiling Mobility and Activity Patterns of Individuals from Multisource Data. J. Transp. Eng. Part A Syst. 2020, 146, 04020025. [CrossRef]

28. McFadden, D.; Train, K. Mixed MNL models for discrete response. J. Appl. Econom. 2000, 15, 447-470. [CrossRef]

29. McClave, J.T.; Benson, P.G.; Sincich, T.; Knypstra, S. Statistiek: Een Inleiding; Pearson: Amsterdam, The Netherlands, 2011.

30. Hensher, D.; Greene, W. The Mixed Logit model: The state of practice. Transportation 2003, 30, $133-176$. [CrossRef]

31. Bierlaire, M. Calculating indicators with PythonBiogeme. Ser. Biogeme 2017, 2017, 1-38. 
32. Philipsen, R.; Schmidt, T.; Van Heek, J.; Ziefle, M. Fast-charging station here, please! User criteria for electric vehicle fast-charging locations. Transp. Res. Part F 2016, 40, 119-129. [CrossRef]

33. CEDelft. Uitbreiding Publieke Laadinfrastructuur tot 2020. Inschatting van het Aantal Benodigde Publieke Laadpunten voor Elektrische Auto's. 2017. Available online: https:/ /www.cbs.nl/nl-nl/maatschappij/verk eer-en-vervoer/transport-en-mobiliteit/infra-vervoermiddelen/vervoermiddelen/categorie-vervoermi ddelen/personenauto-s (accessed on 1 December 2018).

34. Verplanken, B.; Aarts, H. Habit, Attitude, and Planned Behaviour: Is Habit an Empty Construct or an Interesting Case of Goal-directed Automaticity? Eur. Rev. Soc. Psychol. 1999, 10, 101-134. [CrossRef]

35. Wolbertus, R.; Helmus, J.; Maase, S.J.F.M.; Van den Hoed, R. Modes of fast charging: Rolling out fast chargers in cities and along corridors to meet the heterogeneity of needs among EV drivers. In Proceedings of the EVS 31, Kobe, Japan, 1-3 October 2018.

36. NOS. Laadpaalklevers Moeten een Boetetarief Gaan Betalen. 2018. Available online: https://nos.nl/artikel /2261179-laadpaalklevers-moeten-een-boetetarief-gaan-betalen.html (accessed on 1 December 2018).

37. Kelley, S.; Kuby, M. On the way or around the corner? Observed refueling choices of alternative-fuel drivers in Southern California. J. Transp. Geogr. 2013, 33, 258-267. [CrossRef]

Publisher's Note: MDPI stays neutral with regard to jurisdictional claims in published maps and institutional affiliations.

(C) 2020 by the authors. Licensee MDPI, Basel, Switzerland. This article is an open access article distributed under the terms and conditions of the Creative Commons Attribution (CC BY) license (http:/ / creativecommons.org/licenses/by/4.0/). 